\title{
EDITORIAL
}

\section{Introducing Biosphere Clubs}

$\mathrm{R}$ eaders may recall, in the latest Autumn issue of our Journal (Vol. 19, $\mathrm{Nr} 3$, p. 194, 1992), an updating statement of Biosphere Day, following an Editorial entitled 'Biosphere Day and Its Needed Fund and Prizes',* the collective objective of which was to emphasize to our world the quintessential imperative of caring, first and always foremost, for the all-too-fragile Biosphere rather than the far-more-solid remainder of Planet Earth. For it is The Biosphere, rather than the rest of the planet, that constitutes, with the bountiful energy of the Sun, our human and Nature's entire habitat and life-support.

Yet The Biosphere - Mankind and Nature's only proper home - is becoming dangerously threatened by more and increasingly profligate humans on Earth, and by such concomitant subtle menaces as stratospheric ozone depletion, acidic precipitation, and expanding desertification, by 'greenhouse' warming of climate and resultant rising of sea-levels, by all-too-evident and drastic loss of forests and biodiversity, by constriction of cultivable land through modern constructions, concrete highways, and artificial playing-fields, as well as through other 'developmental' menaces whether actual or emerging.

Biosphere Day is accordingly a device having the fundamental objective of reminding thoughtful people everywhere, and ultimately all humanity, on the same meaningful date of September $21 \mathrm{st}^{* *}$ each year, of what they most need to know and practise if they really care about a future for our world — to some extent already for themselves, but particularly for their children and increasingly for any further descendants. With reasonable spacing in time and epitomization of emphasis, Biosphere Day follows the well-established springtime Earth Day and the early-June Environment Day. $\dagger$

To help support our own and, far more important and costly, the efforts of others such as we can hopefully foresee loading up the bandwaggon when once it gets moving, we proposed (in the aforementioned Editorial) a major Biosphere Fund, a leading responsibility of which would be the supplying and administering of Biosphere Prizes, of which the main one would go 'to the winning person or group that is judged to have done the most for The Biosphere through leadership, effective work, or discovery and will be most likely to use such a substantial windfall to do more for that most vital cause. Announcement of the winner or winners of the Prize or Prizes being made each year on Biosphere Day, should give a useful fillip to the latter in a dignified way and ensure due notice by the world's media, though other ways of promotion will of course be sought.'

For lasting effectiveness in the above ways, and in view of the derogation of money-values latterly and foreseeably increasingly in future, the main Biosphere Prize ought to be of at least half-a-million US dollars or, even better, from a sufficient ad hoc endowment to guarantee and administer it, and there should also be about six satellite Biosphere Prizes tied to special component subjects such as Earth Improvements, Air Improvements, Freshwater Improvements, Marine Improvements, Biomass Supply Improvements, and Global Integration Improvements. And whereas the 'main' Biosphere Prize should be strictly so-named, without any prefix other than 'The', each satellite prize could well bear the name of its donor for a minimum of 5 years provided, of course, that both concern and name are fully worthy, as would doubtless be insisted on by our governmental Geneva Cantonal and Swiss Federal supervisors.

The other means by which we are planning the promotion of Biosphere Day and all it stands for is through Biosphere Clubs, the idea for which resulted from a question put to the Chair at a meeting at the Headquarters of the Foundation for Environmental Conservation (FEC) on 24 October 1992, which subsequently discussed possibilities. The report of the meeting, which had been held principally to decide on the near-future strategy of the World Council For The Biosphere (WCB), ended by stating that 'the idea was debated and enthusiastically endorsed, of encouraging local Biosphere lunch or other Clubs as widely as possible in the world, whereupon the Deputy Secretary of the Foundation generously volunteered to organize the first such Club in Geneva. Individually such Biosphere Clubs should be for limited numbers of people desiring to hold group discussions under specialist leaders or with guest speakers, and should be self-supporting and largely autonomous but fostered and collated by FEC' $\$$

We accordingly visualize a network of Biosphere Clubs, of the nature of Rotary or Lions clubs; may they likewise ultimately span the world, foster globally the environmental movement, and bring to everybody the spirit and message of Biosphere Day!

\section{NiCHOLAS POLUNIN}

\footnotetext{
* Editorial: Biosphere Day and Its Needed Fund and Prizes, Environmental Conservation, 19(3), p. 193, 1992.

** The day that 'heralds in the somewhat variable Autumnal Equinox of equal division of night and day in our Planet's Northern Hemisphere ... and similarly the Spring Equinox in the Southern Hemisphere' (Environmental Conservation, 19(3), p. 194, 1992).

$\dagger$ The United Nations Environment Programme's (UNEP's) day of planetary recognition and announcement of the winner or winners of its prestigious and valuable International Sasakawa Environment Prize.

$\S_{c f .}$ Notice: WCB and FEC, Environmental Conservation, 19(4), p. 296, 1992.
} 